\title{
Kajian Karakteristik Morfometri Daerah Aliran Sungai Klawoguk Kota Sorong Berbasis Sistem Informasi Geografis
}

\author{
Anif Farida'; Irnawati Irnawati ${ }^{2}$ \\ ${ }^{1}$ Universitas Muhammadiyah Sorong \\ aniffarida23@gmail.com \\ ${ }^{2}$ Universitas Muhammadiyah Sorong \\ irnawatif@gmail.com
}

\begin{abstract}
Abstrak
DAS Klawoguk yang masuk dalam wilayah Kota Sorong mempunyai permasalahan yang selalu berulang yaitu banjir. Hampir setiap ada hujan yang jatuh dengan intensitas yang cukup tinggi akan mengakibatkan banjir di beberapa lokasi yang dekat dengan sungai. Tujuan penelitian ini untuk mengidentifikasi karakteristik morfometri DAS Klawoguk dengan menggunakan Sistem Informasi Geografis (SIG). Parameter morfometri yang dihitung adalah luas DAS, panjang sungai utama, kemiringan sungai utama, bifurcation ratio, form factor, circularity ratio, drainage density, texture ratio dan length of overland flow. Analisis spasial dilakukan dengan bantuan software MapInfo Professional 11.5 sedangkan analisis dekripstif kualitatif dilakukan dengan cara mengkaji hasil perhitungan morfometri DAS. Hasil penelitian menunjukkan bahwa luas DAS Klawoguk 31,26 km² dengan panjang sungai utama 20,61 km dan kemiringan sungai utama 0,01 (1\%). Nilai $R b$ (bifurcation ratio) sebesar 13,68, form factor sebesar 0,020 yang berarti bentuk DAS tidak bulat dan circularity ratio $(R c) 0,25$ termasuk dalam kategori bentuk DAS memanjang. Kerapatan drainase $3,52 \mathrm{~km} / \mathrm{km}^{2}$ masuk dalam kelas sedang, nilai texture ratio 3,87 dan nilai length of overland flow sebesar 1,76. Berdasarkan parameter morfometri tersebut DAS Klawoguk mempunyai kenaikan debit banjir yang cepat dengan air tidak tergenang terlalu lama, volume runoff yang dihasilkan juga cukup besar, kemampuan infiltrasi yang rendah dan durasi waktu yang diperlukan oleh aliran untuk mencapai outlet tidak terlalu cepat.
\end{abstract}

Kata kunci: morfometri; DAS; Sistem Informasi Geografis

\section{PENDAHULUAN}

Permasalahan daerah aliran sungai saat ini semakin beragam dan sangat mengkhawatirkan. Banjir dan tanah longsor merupakan peristiwa yang seringkali terjadi bila musim penghujan tiba. Timbulnya bencana secara tidak langsung disebabkan oleh gangguan keseimbangan yang terjadi di dalam sistem DAS dan merupakan respon komponen DAS terhadap curah hujan yang jatuh (input). Suprayogi, et. al (2013) mengemukakan bahwa DAS merupakan ekosistem yang didalamnya terdapat unsur-unsur baik fisik maupun non fisik yang saling berinteraksi dan ada keseimbangan antara aliran yang masuk dengan aliran yang keluar. Sistem DAS tidak hanya terdiri dari satu komponen saja, sehingga untuk mengetahui permasalahan yang 


\section{Median Volume 12 Nomor 2 Bulan Juni 2020}

ada di DAS tersebut semua komponen yang berpengaruh perlu diamati dan ditelaah dengan cermat.

Karakteristik DAS merupakan ciri khas dari daerah aliran yang dapat berupa karakteristik fisik, karakteristik sosial maupun budaya yang ada dalam masyarakat. Karakteristik fisik merupakan dasar untuk menentukan bagaimana kondisi hidrologi. Adapun karateristik sosial budaya merupakan faktor dinamis yang dapat berpengaruh negatif ataupun positif terhadap aspek hidrologi di dalam DAS. Pemahaman mengenai karakteristik fisik DAS sangat penting untuk mencari solusi berbagai persoalan dalam pengeloaan DAS dan dapat menjadi pertimbangan alternatif bagaimana pengembangan wilayah DAS dengan memperhatikan keseimbangan antara input dan output.

Morfometri DAS pada dasarnya merupakan karakteristik fisik dari DAS yang berkaitan dengan kondisi geologi dan geomorfologi. Karakteristik ini berhubungan dengan proses meresapnya air hujan yang jatuh ke dalam tanah. Parameter tersebut diantaranya luas, bentuk DAS, jaringan sungai, kerapatan aliran, pola aliran dan gradien sungai (Rahayu, et.al 2009). Analisis kuantitatif morfometri dapat digunakan untuk memberikan informasi hidrologi alami dari berbagai batuan yang ada di DAS. Peta drainase menyediakan indeks permeabilitas dari batuan dan keterkaitan antara tipe batuan, struktur dan status kondisi hidrologinya. Karakteristik DAS dan manajemennya memerlukan informasi yang detail mengenai topografi, jaringan sungai, water divide, panjang saluran, geomorfologi dan geologi untuk mengatur pengelolaan DAS dan implementasi perencanaan untuk konservasi air (Sreedevi, et. al. 2013).

Informasi mengenai data-data Daerah Aliran Sungai akan sulit dikumpulkan dan dihitung parameter morfometrinya jika menggunakan cara konvensional. Hal ini dikarenakan cara tersebut memerlukan dana yang tidak sedikit karena perlu persiapan alat dan tenaga dalam jumlah banyak serta waktu yang lama untuk menyelesaikan pengambilan data. Salah satu cara yang memudahkan untuk mendapatkan parameter morfometri adalah dengan menggunakan teknologi Sistem Informasi Geografis. Javed, et. al. (2009) menyatakan bahwa kemajuan teknologi berbasis komputer yang tepat telah dicapai dengan menggunakan teknologi canggih seperti sistem informasi geografis dan peralatan terkait untuk penentuan otomatis parameter DAS yang lebih efisien, akurat dan dapat diandalkan.

DAS Klawoguk yang masuk dalam wilayah Kota Sorong mempunyai permasalahan yang cukup pelik dan berulang terus menerus yaitu banjir. Hampir setiap ada hujan yang jatuh dengan intensitas yang cukup tinggi akan mengakibatkan banjir di beberapa lokasi yang dekat dengan sungai. Berdasarkan hal tersebut maka tujuan penelitian ini untuk mengidentifikasi karakteristik morfometri DAS Klawoguk dengan menggunakan Sistem Informasi Geografis (SIG). Informasi mengenai morfometri diharapkan dapat menjadi bahan referensi mengenai kondisi hidrologi dan memberikan alternatif pengelolaan DAS yang tepat dengan melihat karakteristik fisik sehingga bencana banjir dapat diminimalisir. 


\section{METODE PENELITIAN}

\section{Lokasi Penelitian}

DAS Klawoguk secara geografis terletak antara $131,2866554^{\circ}$ BT $131,3865770^{\circ} \mathrm{BT}$ dan $0,86706396^{\circ} \mathrm{LS}-0,95255829^{\circ} \mathrm{LS}$. Secara administrasi masuk ke dalam wilayah Kota Sorong dan mencakup wilayah Distrik Sorong Utara dan Distrik Sorong Timur. Batas administrasinya yaitu sebelah utara berbatasan dengan DAS Klagison, sebelah timur berbatasan dengan DAS Klasaman, sebelah selatan berbatasan dengan DAS Warmon dan sebelah barat berbatasan dengan Selat Dampir.

Kondisi iklim DAS Klawoguk secara umum sama dengan Kota Sorong dan dapat dilihat dari besarnya curah hujan, suhu dan kelembaban. Berdasarkan data dari Badan Meteorologi Klimatologi dan Geofisika tahun 2019 Kota Sorong memiliki suhu rata-rata terendah di bulan Juli sebesar 25,6 ${ }^{\circ} \mathrm{C}$ sedangkan suhu tertinggi $28,0{ }^{\circ} \mathrm{C}$ di bulan November dan Desember. Kelembaban rata-rata terendah 81,5\% di bulan Maret dan tertinggi 89,7\% di bulan Juli. Curah hujan tertinggi terjadi pada bulan Juni sebesar $362 \mathrm{~mm}$ dan terendah 76,7 $\mathrm{mm}$ di bulan September.

Menurut Peta Tanah dari Pusat Penelitian dan Pengembangan Tanah dan Agroklimat, DAS Klawoguk terdiri dari tiga lima jenis tanah yaitu Dystropepts, Eutropepts, Tropaquent, Troporthents dan Tropudalfs. Peta Geologi menunjukkan di DAS Klawoguk terdapat tiga formasi batuan yaitu Qa (Endapan Alluvium dan Litoral), TQk (Formasi Klasaman) dan Qps (Konglomerat Sele).

\section{Bahan dan Alat Penelitian}

Bahan yang digunakan dalam penelitian ini meliputi Peta Rupa Bumi Digital Indonesia Skala 1 : 50.000, Peta Tanah, Peta Geologi dan data meterorologi klimatologi. Alat yang digunakan yaitu perangkat keras komputer Intel, Software Microsoft Office 2010 dan software MapInfo Professional 11.5.

\section{Pengumpulan Data}

Teknik pengumpulan data dalam penelitian ini yaitu untuk Peta Rupa Bumi Digital Indonesia diperoleh dari Badan Informasi Geospasial. Peta Tanah dan Peta Geologi diperoleh dari Pusat Penelitian dan Pengembangan Tanah dan Agroklimat sedangkan data meteorologi klimatologi diperoleh dari Badan Meteorologi Klimatologi dan Geofisika (BMKG).

\section{Pengolahan Data}

\section{Luas DAS}

Daerah Aliran Sungai dibatasi oleh igir pegunungan yang berfungsi sebagai batas (river divide) dan akhirnya mengalirkan air hujan yang bertemu pada satu outlet. Cara menghitung luas DAS dengan menentukan terlebih dahulu outlet DAS dan membuat delineasi garis batas DAS pada igir tertentu mulai dari titik outlet sampai hulu DAS menggunakan software MapInfo Professional 11.5. Selanjutnya luas DAS dihitung 


\section{Median Volume 12 Nomor 2 Bulan Juni 2020}

Doi http://doi.org/md.v12i2.941

dengan menggunakan Tools yang ada dalam software dan hasilnya dapat dilihat pada atribut peta.

\section{Panjang Sungai Utama (Stream Length)}

Panjang sungai utama (L) diukur dari outlet sungai ke ujung DAS di hulu. Apabila ada pertemuan dua sungai, mengikuti cara Horton sebagai berikut:

a. Apabila sudut sama $\left(\phi_{1}=\phi_{2}\right)$, maka pilihlah sungai yang lebih panjang.

b. Apabila sudut tidak sama, maka pilihlah sudut yang kecil (misal $\theta_{4}>\theta_{3}$, pilih sungai pada sudut $\theta_{3}$.

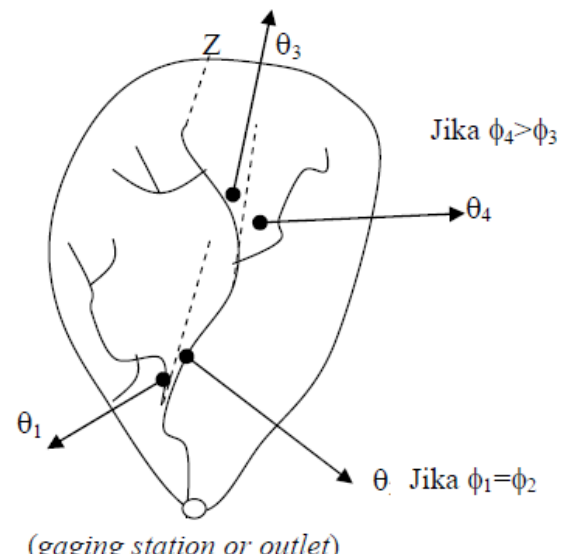

Gambar 1. Penentuan Sungai Utama (Seyhan, 1977)

\section{Kemiringan Sungai Utama (Main Stream Length)}

Kemiringan sungai dapat dihitung dengan cara average slope (Seyhan, 1977) sebagai berikut:

$$
S=\frac{H}{L}
$$

Keterangan :

$\mathrm{S}$ : perbandingan dari selisih tinggi antara tempat terjauh dan tempat pengamatan terhadap L.

L : panjang jarak dari tempat terjauh di daerah aliran sampai tempat pengamatan banjirnya, diukur menurut jalannya sungai (meter).

$\mathrm{H}$ : selisih ketinggian antara tempat terjauh dan tempat pengamatan (meter).

\section{Bifurcation Ratio (Rb)}

Tingkat percabangan sungai menggambarkan banyak sedikitnya jumlah alur sungai yang ada dalam suatu DAS. Sebelum menghitung Bifurcation Ratio $(\mathrm{Rb})$ terlebih dahulu harus menentukan orde sungai. Strahler (1952) mengemukakan segmen yang tidak memiliki percabangan merupakan orde pertama. Ketika dua segmen orde-pertama bergabung, maka akan terbentuk orde kedua. Dua segmen orde - dua akan membentuk orde - tiga. Dua orde - tiga akan membentuk orde - empat, dan seterusnya. Setiap 


\section{Median Volume 12 Nomor 2 Bulan Juni 2020}

Doi http://doi.org/md.v12i2.941

segmen dapat ditempel oleh orde dengan nilai yang lebih kecil namun tidak akan merubah atau meningkatkan nilai ordenya. Rumus untuk menghitung Bifurcation Ratio (Rb) menurut Schumn (1956) sebagai berikut :

$$
R b=\frac{N u}{N u+1}
$$

Untuk memperoleh nilai $\mathrm{Rb}$ keseluruhan DAS, maka digunakan rerata tertimbang :

$$
W_{R b}=\frac{\sum R b_{u / u+1}\left(N_{u}+N_{u+1}\right)}{N_{u}}
$$

Keterangan :

$\mathrm{Rb} \quad$ : Bifurcation ratio

$\mathrm{Nu} \quad$ : Jumlah segmen sungai orde ke u

$\mathrm{Nu}+1$ : Jumlah segmen sungai orde yang lebih tinggi (orde ke $\mathrm{u}+1$ )

\section{Form Factor (Rf)}

Horton (1932) mengemukakan rumus untuk menghitung Form Factor sebagai berikut :

$$
R f=\frac{A}{(L b)^{2}}
$$

Keterangan :

Rf : Form Factor

A Area of the basin (luas DAS) $\left(\mathrm{km}^{2}\right)$

$\mathrm{Lb} \quad$ : Basin Length (keliling DAS) $(\mathrm{km})$

\section{Circularity Ratio (Rc)}

Miller (1953) dalam Rekha et.al (2011) mendefinisikan Circularity Ratio (Rc) rasio antara luas DAS dengan luas lingkaran yang memiliki lingkar yang sama dengan perimeter DAS seperti persamaan berikut :

$$
R c=\frac{4 \pi A}{(P)^{2}}
$$

Keterangan :

Rc : Circularity Ratio

A : Area of the basin (luas DAS) $\left(\mathrm{km}^{2}\right)$

$\mathrm{P} \quad$ : Perimeter DAS $(\mathrm{km})$

\section{Drainage Density (Dd)}

Drainage density adalah panjang aliran sungai per kilometer persegi luas DAS. Semakin besar nilai Dd semakin baik sistem pengaliran (drainase) di daerah tersebut. Rumus untuk menghitung Dd menurut Seyhan (1977) : 


$$
\operatorname{Dd}=\frac{\Sigma L_{n}}{A}
$$

Keterangan :

Dd : kerapatan drainase $\left(\mathrm{km} / \mathrm{km}^{2}\right)$

$\mathrm{L}_{\mathrm{n}} \quad$ : panjang sungai $(\mathrm{km})$

A : luas DAS $\left(\mathrm{km}^{2}\right)$

\section{Texture Ratio}

Tekstur DAS diperoleh dari total segmen alur sungai orde pertama dibagi dengan keliling DAS seperti yang dikemukakan oleh Horton (1932) :

$$
T=\frac{N 1}{P}
$$

Keterangan :

N1 : Jumlah sungai orde 1

P : Keliling DAS (km)

\section{Length of Overland Flow (Lof)}

Indarto (2016) menyebutkan bahwa length of overland flow merupakan jumlah kumulatif air hujan yang mengalir di atas permukaan Daerah Aliran Sungai. Menurut Horton (1945) rumus yang digunakan untuk menghitung Length of Overland Flow:

$$
L o f=\frac{1}{2} D d
$$

Keterangan :

Lof : Length of Overland Flow

Dd : Drainage density $\left(\mathrm{km} / \mathrm{km}^{2}\right)$

\section{Analisis Data}

Analisis data yang digunakan dalam penelitian ini berupa analisis spasial dan analisis deskripstif kualitatif. Analisis spasial dilakukan dengan bantuan software Sistem Informasi Geografis yaitu MapInfo Professional 11.5. Di dalam MapInfo terdapat tools yang sangat membantu dalam pengukuran terutama parameter morfometri DAS. Selain itu dengan analisis spasial dapat diketahui sebaran dari masing-masing komponen yang digunakan untuk menentukan tiap parameter morfometri.

Analisis deskriptif kualitatif dilakukan dengan cara mengkaji hasil perhitungan morfometri DAS Klawoguk. Nilai dari masing-masing parameter morfometri dicocokkan dengan literatur sehingga diperoleh gambaran kondisi DAS yang diteliti. Gambaran yang dimaksud disini adalah kondisi fisik DAS yang berpengaruh terhadap aliran. Tahapan penelitian disajikan pada Gambar 2. 


\section{Median Volume 12 Nomor 2 Bulan Juni 2020}

Doi http://doi.org/md.v12i2.941

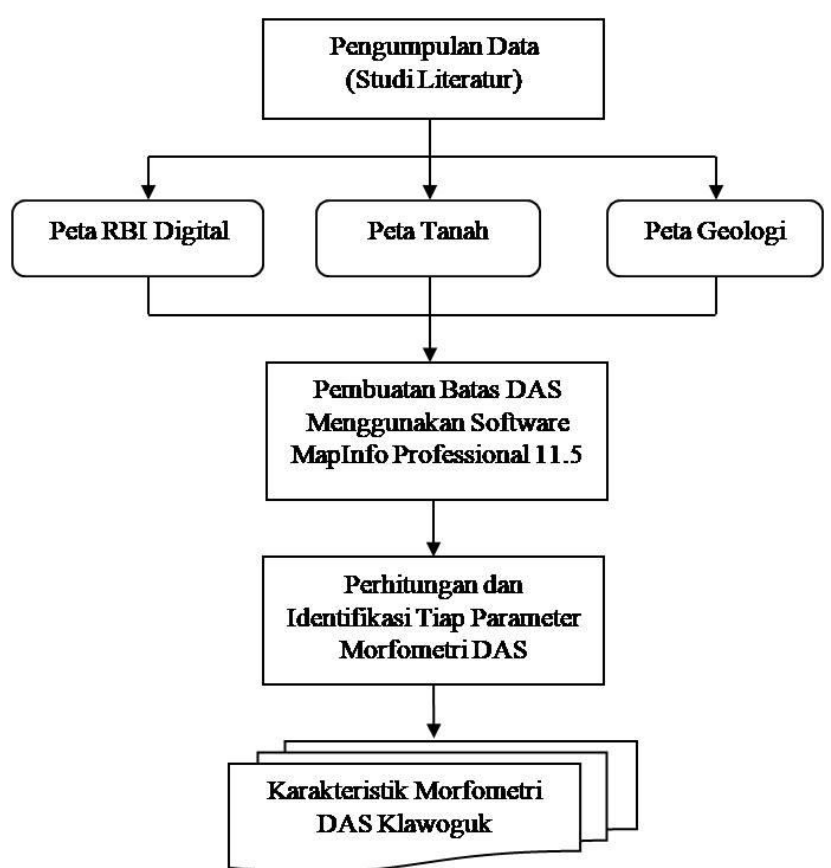

Gambar 2. Tahapan Penelitian

\section{HASIL DAN PEMBAHASAN}

Morfometri DAS merupakan kondisi hidrologi berdasarkan aspek fisik dan sangat penting dalam kajian aliran permukaan terutama banjir. Hal ini disebabkan faktor-faktor fisik suatu DAS mempunyai pengaruh terhadap kondisi aliran permukaannya. Selain itu, perubahan faktor-faktor fisik DAS dapat menjadi indikasi terjadinya perubahan aliran permukaan.

\section{Luas DAS}

Luas DAS sangat berpengaruh terhadap daya tangkap hujan yang jatuh. Semakin besar luas suatu DAS berarti semakin banyak pula curah hujan jatuh di DAS tersebut dibandingkan dengan DAS dengan luas yang lebih kecil. Besar kecilnya daya tangkap terhadap hujan yang jatuh ini ternyata berpengaruh terhadap volume aliran permukaan yang terjadi. Semakin luas DAS, daya tangkap semakin besar, sehingga volume aliran permukaan yang dihasilkan semakin banyak. Sebaliknya, semakin kecil DAS maka daya tangkap semakin kecil terhadap hujan yang jatuh. Oleh karena itu, volume air pemukaan yang tertampung di DAS tersebut juga sedikit.

DAS Klawoguk mempunyai luas $31,26 \mathrm{~km}^{2}$, yang diperoleh dari perhitungan Peta Rupa Bumi Digital Indonesia skala 1 : 50.000 dengan menggunakan sofware Sistem Informasi Geografis (MapInfo Professional 11.5). Berdasarkan luas DAS tersebut maka DAS Klawoguk dapat dikategorikan cukup luas. Dengan luasan 31,26 $\mathrm{km}^{2}$ tersebut diasumsikan bahwa curah hujan yang jatuh banyak yang tertampung sehingga volume aliran permukaannnya besar. Akan tetapi kadang-kadang luas belum tentu menjadi indikasi banyak sedikitnya volume aliran permukaan karena ada faktor lain yang juga 


\section{Median Volume 12 Nomor 2 Bulan Juni 2020}

Doi http://doi.org/md.v12i2.941

berpengaruh. Oleh karena itu, untuk menilai banyak sedikitnya aliran permukaan tidak hanya ditinjau dari segi luas saja akan tetapi juga perlu mempertimbangkan komponen lain misal kondisi nonfisik wilayah.

\section{Panjang Sungai Utama (Stream Length)}

Panjang sungai utama diukur mulai dari outlet sampai ujung sungai di daerah hulu. Pada penelitian ini panjang sungai utama ditentukan dengan bantuan software MapInfo Professional 11.5 dan diperoleh panjang sungai utama DAS Klawoguk yaitu 20,61 km. Panjang sungai utama berpengaruh terhadap waktu konsentrasi yaitu durasi waktu yang dibutuhkan oleh aliran air untuk mengalir dari titik paling jauh yang ada di hulu sampai ke tempat keluaran (outlet). Semakin panjang sungai utama, waktu konsentrasinya lebih lama dibanding sungai utama yang pendek. Sungai utama yang panjang kemungkinan terjadinya banjir juga relatif lebih kecil. Hal ini dikarenakan air hujan yang jatuh memerlukan waktu yang lama agar seluruh daerah alirannya berperan dalam membentuk aliran. Peta Sungai Utama di DAS Klawoguk disaiikan pada Gambar 3.

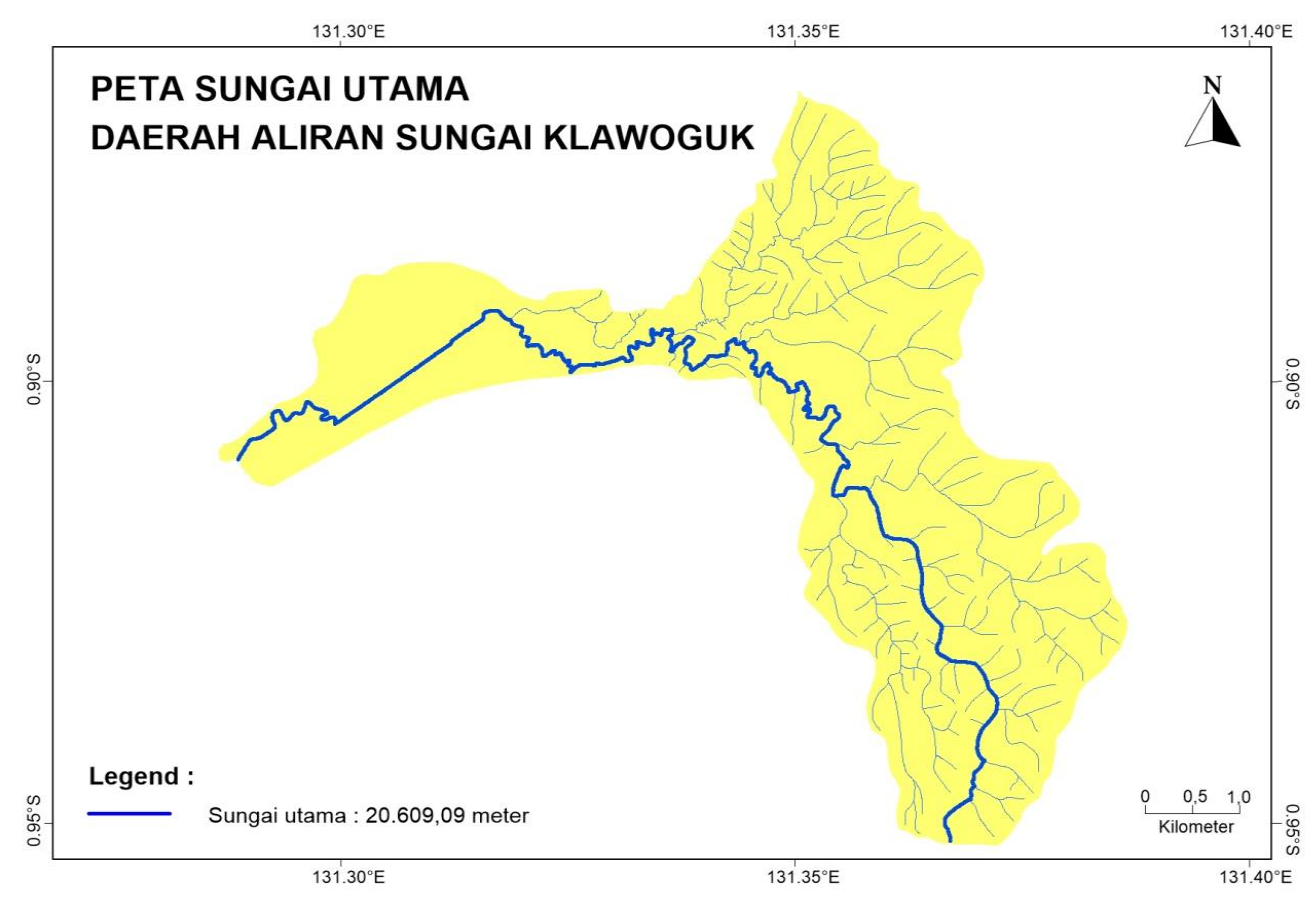

Gambar 3. Peta Sungai Utama

\section{Kemiringan Sungai Utama (Main Stream Gradien)}

Kemiringan sungai utama merupakan perbandingan antara beda tinggi sungai utama di bagian hulu dengan beda tinggi sungai utama di bagian hilir terhadap panjang sungai utama. Besar kecilnya kemiringan sungai utama ini berpengaruh terhadap kecepatan aliran. Kemiringan sungai utama yang tinggi menunjukkan aliran air cepat keluar mencapai outlet. 


\section{Median Volume 12 Nomor 2 Bulan Juni 2020}

Doi http://doi.org/md.v12i2.941

Berdasarkan hasil perhitungan diketahui bahwa DAS Klawoguk kemiringan sungai utamanya sebesar 0,01 (1\%). Kemiringan tersebut mengindikasikan bahwa aliran (runoff) membutuhkan waktu yang lama agar sampai ke hilir. Kemiringan yang rendah juga mengakibatkan akumulasi air yang dapat menyebabkan terjadinya genangan di wilayah khususnya daerah cekungan di dalam DAS.

\section{Bifurcation Ratio $(\boldsymbol{R b})$}

Horton mendefinisikan orde sungai adalah gambaran tingkat percabangan sungai orde ( ke U) dengan ordo sungai berikutnya yang lebih tinggi (ke $U+1)$ (Seyhan, 1990). Orde sungai ini menggambarkan posisi alur sungai dalam suatu DAS. Persebaran orde sungai di DAS Klawoguk disajikan pada Gambar 4.

Hasil perhitungan menunjukkan nilai Rb DAS Klawoguk sebesar 13,68 seperti yang tertera pada Tabel 1. Berdasarkan kajian dari Strahler (1964) nilai tersebut masuk dalam kategori $\mathrm{Rb}>5$ dimana alur tersebut memiliki kenaikan debit banjir yang cepat, demikian juga dengan penurunannya akan berjalan dengan cepat. Hal ini berarti apabila terjadi hujan yang cukup deras di DAS Klawoguk, maka air akan mengalami kenaikan debit puncak yang cepat dan penurunan debit yang cepat pula. Dengan kata lain waktu untuk terjadinya banjir juga singkat. Volume air yang tergenang diasumsikan tidak banyak karena air cepat surut sehingga tidak menimbulkan akumulasi air dalam jumlah besar. Meskipun demikian, hal ini tidak bisa dijadikan patokan mengingat banyak sedikitnya air yang tergenang dipengaruhi juga oleh tekstur tanah dan formasi batuan.

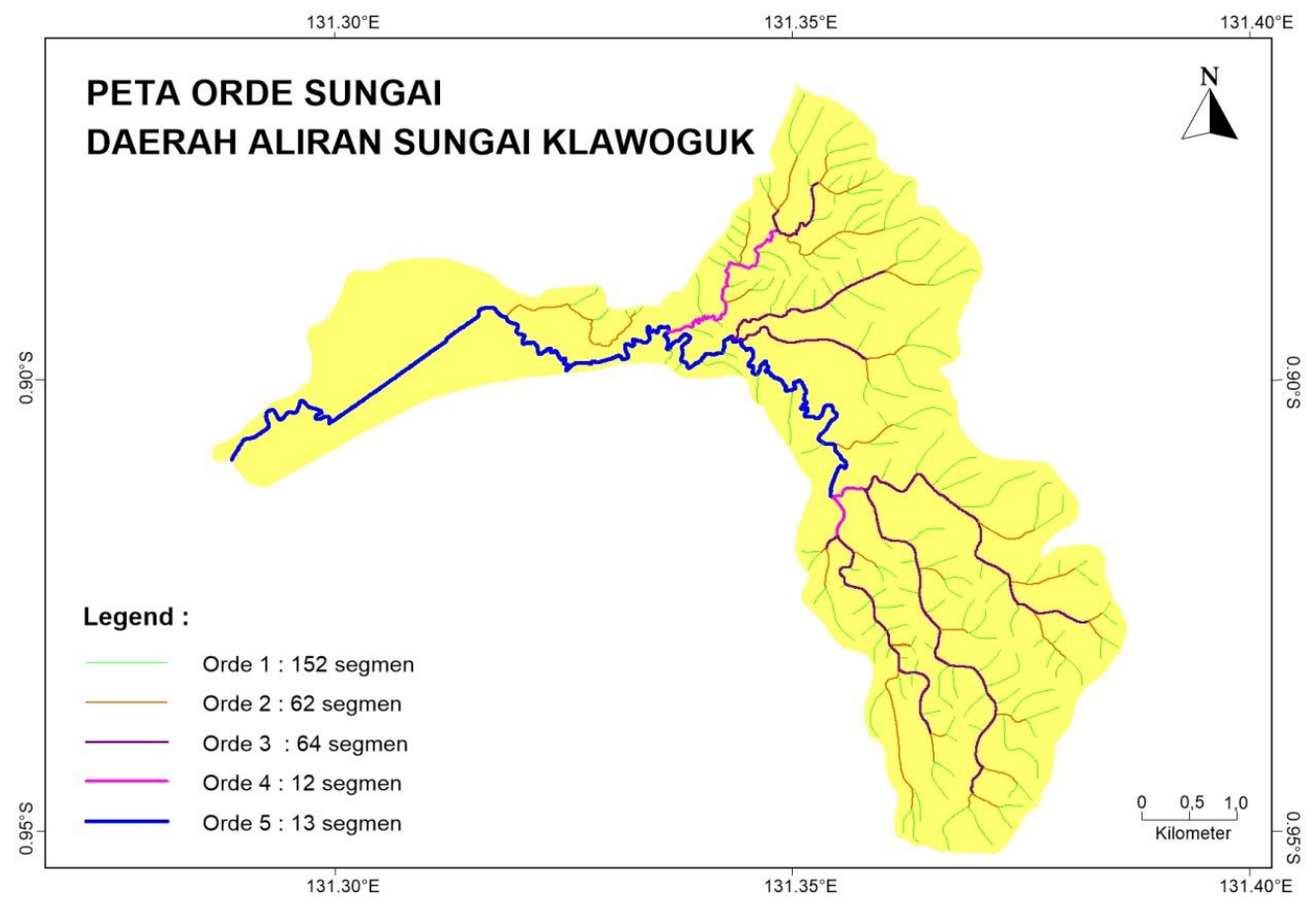

Gambar 4. Peta Orde Sungai 


\section{Median Volume 12 Nomor 2 Bulan Juni 2020}

Doi http://doi.org/md.v12i2.941

Tabel 1. Nilai Rb

\begin{tabular}{cccc}
\hline Orde sungai & Jumlah Segmen & $\mathrm{Rb}$ & $\mathrm{Rb}^{*}(\mathrm{Nu}+\mathrm{Nu}+1) / \mathrm{Nu}$ \\
\hline 1 & 152 & 2,45 & 3,45 \\
2 & 62 & 0,97 & 1,97 \\
3 & 64 & 5,33 & 6,33 \\
4 & 12 & 0,92 & 1,92 \\
5 & 13 & & 13,68
\end{tabular}

Sumber : Data Primer yang diolah

\section{Form Factor}

Form factor merupakan salah satu parameter yang digunakan untuk memprediksi intensitas aliran yang terjadi dalam suatu daerah aliran. Nilai form factor yang tinggi menunjukkan bahwa DAS tersebut mempunyai bentuk yang membulat. Hasil perhitungan menunjukkan bahwa Form Factor DAS Klawoguk sebesar 0,020. Berdasarkan nilai tersebut diketahui jika DAS Klawoguk mempunyai bentuk yang tidak bulat atau membulat. Bahkan jika dilihat pada Gambar 4 terlihat jika bentuk DAS mempunyai kecenderungan memanjang hampir menyerupai kipas. Daerah aliran tersebut dicirikan dengan debit banjir yang relatif kecil dikarenakan waktu untuk terjadinya banjir dari anak-anak sungai tidak bersamaan.

\section{Circularity Ratio (Rc)}

Pola aliran sangat berpengaruh terhadap volume aliran yang terjadi di sungai dan bentuk DAS yang bersangkutan. Penentuan bentuk DAS ini sulit untuk dinyatakan secara kualitatif sehingga digunakan pendekatan Circularity Ratio (Rc). Berdasarkan hasil perhitungan DAS Klawoguk mempunyai nilai Rc 0,25. Menurut klasifikasi Soewarno (1991) seperti yang tertera pada Tabel 2, nilai tersebut menunjukkan bahwa bentuk DAS Klawoguk memanjang. Bentuk DAS yang demikian mempunyai kecenderungan kenaikan debit banjir tidak cepat atau laju aliran permukaan agak lambat sehingga konsentrasi air juga lambat.

Tabel 2. Nilai Circularity Ratio $(R c)$

\begin{tabular}{ccl}
\hline No. & Rc & \multicolumn{1}{c}{ Keterangan } \\
\hline 1 & $>0,5$ & $\begin{array}{l}\text { Bentuk Daerah Aliran Sungai membulat, waktu untuk mencapai debit } \\
\text { puncak lama, begitu juga waktu resesinya (turun) } \\
\text { Bentuk Daerah Aliran Sungai memanjang, waktu terjadinya debit puncak } \\
\text { cepat, begitu juga waktu resesinya (turun) }\end{array}$ \\
\hline
\end{tabular}

Sumber : Soewarno, 1991

\section{Drainage Density (Dd)}

Kerapatan drainase menunjukkan cepat keringnya suatu DAS atau mengalami penggenangan. Menurut hasil perhitungan diketahui bahwa DAS Klawoguk mempunyai kerapatan drainase 3,52 km/ $\mathrm{km}^{2}$. Menurut klasifikasi Linsley (1949), DAS Klawoguk nilai Dd termasuk dalam kategori baik dan tidak pernah mengalami pengganangan 


\section{Median Volume 12 Nomor 2 Bulan Juni 2020}

Doi http://doi.org/md.v12i2.941

dalam waktu yang lama. Demikian juga berdasarkan klasifikasi dari Sriyana (2013) masuk dalam kelas sedang seperti yang disajikan pada Tabel 3 sedangkan persebaran spasial jaringan sungai dapat dilihat pada Gambar 5.

Tabel 3. Klasifikasi Kerapatan Aliran

\begin{tabular}{ccc}
\hline No. & $\mathrm{Dd}\left(\mathrm{km} / \mathrm{km}^{2}\right)$ & Kelas Kerapatan \\
\hline 1 & $<0,25$ & Rendah \\
2 & $0,25-10$ & Sedang \\
3 & $10-25$ & Tinggi \\
4 & $>25$ & Sangat tinggi \\
\hline
\end{tabular}

Sumber : Sriyana, 2013

Kerapatan drainase menunjukkan banyak sedikitnya alur-alur sungai yang ada sehingga jika alur sungainya banyak maka aliran permukaan juga banyak. Selain itu, nilai Dd dapat menjadi indikasi resistensi batuan. Nilai Dd rendah, alur sungai melewati batuan dengan resistensi keras, maka material sedimen yang terikut aliran lebih kecil jika dibandingkan pada alur sungai yang melewati batuan dengan resistensi lunak. Nilai Dd yang sangat tinggi, berarti alur sungainya melewati batuan yang tidak meloloskan air (impermeable). Keadaan ini menunjukkan bahwa air hujan yang menjadi direct runoff juga besar.

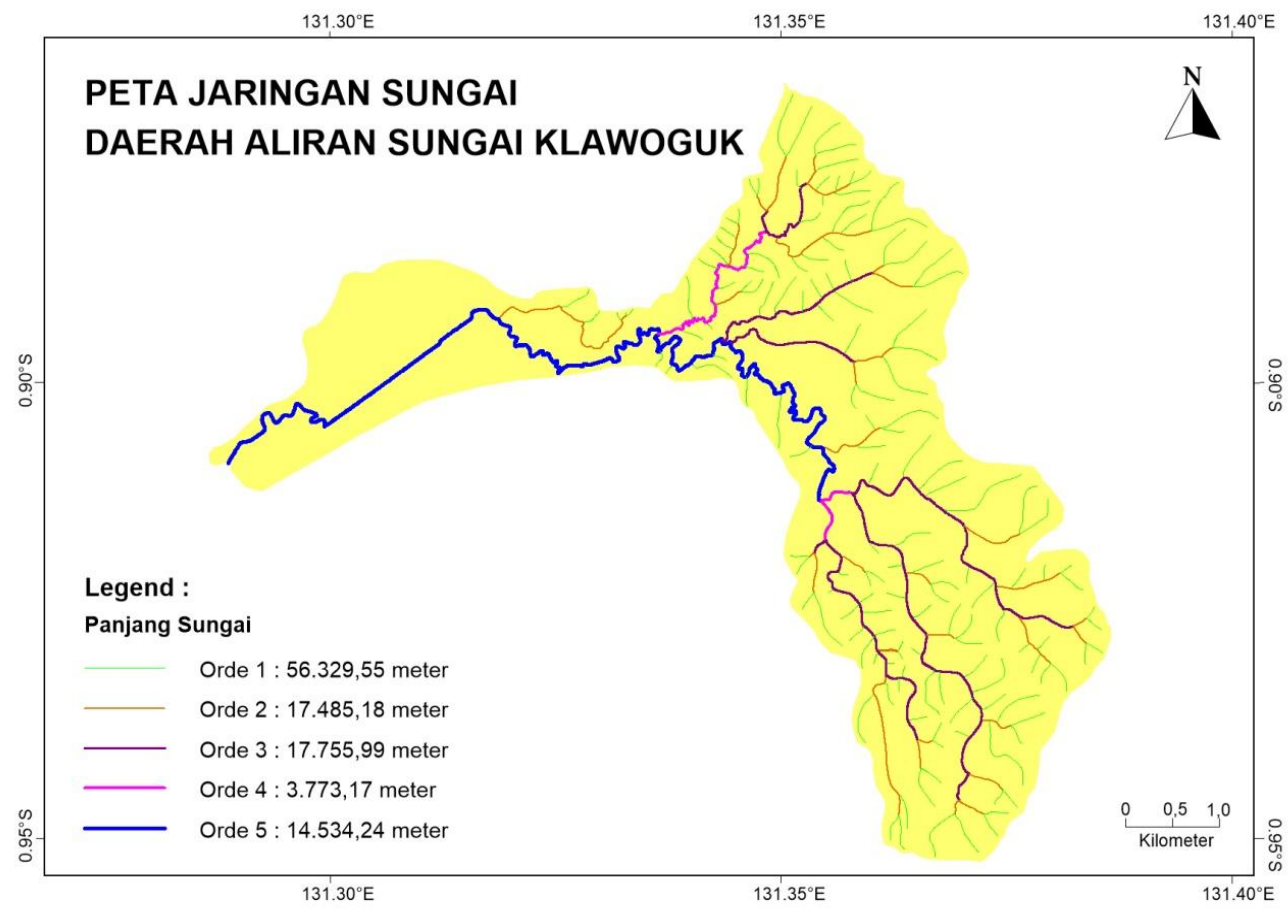

Gambar 5. Peta Jaringan Sungai

\section{Texture Ratio}

Tekstur DAS mempunyai pengaruh yang cukup besar terhadap kemampuan meresapkan air ke dalam lapisan tanah (kapasitas infiltrasi). Menurut Rahayu et, al (2009) nilai texture ratio yang rendah menggambarkan kemampuan infiltrasi yang 
rendah dan kemiringan yang rendah. Sedangkan nilai texture ratio yang tinggi menunjukkan kemiringan yang tinggi dengan kemampuan infiltrasi yang tinggi pula.

Hasil perhitungan nilai texture ratio DAS Klawoguk sebesar 3,87 sehingga mengindikasikan bahwa DAS tersebut mempunyai kemampuan infiltrasi yang rendah. Hal ini diperkuat dengan fakta bahwa kondisi geologi di DAS Klawoguk didominasi oleh batuan kapur yang terbentuk pada masa kuarter. Material pembentuk tanah juga disusun oleh batuan diabaas, kuarter, neogen dan terdapat juga batu gamping yang membentuk bukit-bukit. Sifat dari batuan kapur mempunyai laju infiltrasi yang relatif kecil karena permeabilitas atau sifat kelolosan airnya rendah. Apabila ada hujan jatuh maka sebagian besar akan mengalir sebagai aliran permukaan (overland flow). Jenis batuan juga berpengaruh terhadap bentuk hidrograf aliran. DAS dengan batuan kapur atau batu gamping bersifat porous menyebabkan hidrograf aliran yang berbentuk landai dengan debit puncak yang rendah dan waktu konsentrasi yang lebih lama.

\section{Length of Overland Flow}

Length of Overland Flow merupakan panjang aliran air di permukaan tanah sebelum mencapai sungai. Nilai Lof DAS Klawoguk 1,76 yang berarti aliran air tidak terlalu cepat untuk mencapai saluaran ataupun sungai. Dengan demikian potensi untuk terjadinya banjir juga relatif rendah. Semakin rendah nilai Lof maka panjang aliran air yang dilalui pendek sehingga waktu tempuh agar keseluruhan air mencapai sungai juga singkat. Kondisi ini menyebabkan daerah tersebut rentan terhadap tingginya aliran permukaan. Banyaknya aliran permukaan yang terjadi akan menyebabkan banjir. Hal ini perlu menjadi perhatian khusus terlebih jika turun hujan dengan intensitas tinggi karena volume runoff yang terjadi juga akan semakin besar.

\section{KESIMPULAN}

DAS Klawoguk ditinjau dari parameter morfometri seperti luas DAS, panjang sungai utama, kemiringan sungai utama, kerapatan drainase, bentuk DAS, panjang aliran permukaan dan tingkat percabangan sungai mempunyai kenaikan debit banjir yang cepat dengan air tidak tergenang terlalu lama. Volume runoff yang dihasilkan juga cukup besar karena luasnya daerah tangkapan hujan dengan kemampuan infiltrasi yang rendah. Durasi waktu yang diperlukan oleh aliran untuk mencapai outlet tidak terlalu cepat.

Sistem Informasi Geografis berperan penting dalam menghitung parameter morfometri DAS dengan catatan data spasial yang tersedia lengkap dan paling mutakhir. Tools yang ada dalam software sangat membantu sehingga tidak perlu dilakukan perhitungan secara manual. Selain itu, dengan sifatnya yang real-time data morfometri yang diperoleh dari SIG merupakan gambaran kondisi sesungguhnya yang ada di lapangan. 


\section{Median Volume 12 Nomor 2 Bulan Juni 2020}

Doi http://doi.org/md.v12i2.941

\section{DAFTAR PUSTAKA}

Horton, R.E. 1932. Drainage Basin Characteristics. Tansactions of American Geophysical Association, 13, pp. 350-36.1

Horton, R.E. 1945. Erosional Development of Streams and Their Drainage Basins; Hydrophysical Approach to Quantitative Morphology. Geological Society of America Bulletin. 56(3):275-370.

Indarto. 2016. Hidrologi : Metode Analisis dan Tool Untuk Interpretasi Hidrograf Aliran Sungai. PT. Bumi Aksara. Jakarta.

Javed A, Khanday MY, Ahmed R. 2009. Prioritization of subwatershed based on morphometric and land use analysis using remote sensing and GIS techniques. $J$ Indian Soc Remote Sens

37:261-274.

Linsley, R.K. 1949. Applied Hydrology. McGraw Hill Book Co. New York

Rahayu, S. et.al. 2009. Monitoring Air Di Daerah Aliran. World Agroforestry Center. Bogor.

Rekha, V. B. George, A. V. And Rita, M. 2011. Morphometric Analysis and Microwatershed Prioritization of Peruvanthanam Sub-watershed, the Manimala River Basin, Kerala, South India. Environmental Research, Engineering and Management, 2011. No. 3(57), pp. 6-14.

Schumm, S.A. 1956. Evolution of Drainage Systems and Slopes in Badlands at Perth Amboy. Geological Society of America, New Jersey. Vol .67.

Seyhan, E. 1977. A Mophometrical Analysis In The Ardeche River Basin, Southern France. Geographical Institute. Utrech.

Seyhan E., 1990. Dasar-Dasar Hidrologi. Gadjah Mada University Press. Yogyakarta.

Soewarno. 1991. Hidrologi: Pengukuran dan Pengolahan Data Aliran Sungai, (Hidrometri). Nova. Bandung.

Sreedevi PD, Sreekanth PD, Khan HH, Ahmed S. 2013. Drainage morphometry and its influence on hydrology in an semi-arid region: using SRTM data and GIS. Environ Earth Sci 70(2):839-848.

Sriyana, 2011, Kajian Karakteristik DAS Tuntang dan Model Pengelolaan DAS Terpadu, TEKNIK - Vol.32 No.3, ISSN 0852-1697.

Strahler, A. N. 1952. Hypsometric (Area-Altitude) Analysis of Erosional Topography. Bull Geol, Soc Am 63.

Strahler, A.N. 1964. Quantitative Geomorphology of Drainage Basins and Channel Networks; Handbook of applied hydrology. McGraw- Hill Book Cooperation, New York.

Suprayogi, S., Purnama, Ig.I. dan Darmanto, D. 2013. Pengelolaan Daerah Aliran Sungai. Gadjah Mada University Press. Yogyakarta. 